\title{
Profile of Glaucoma at The Dr.M.Djamil Hospital Padang, West Sumatera
}

\author{
Andrini Ariesti, Diska Herriadi
}

\section{Abstrak}

Glaukoma adalah kelompok penyakit yang memiliki kesamaan karakteristik terkait optik neuropati dengan kehilangan fungsi penglihatan. Objektif: Untuk menggambarkan distribusi glaukoma di RSUP DR. M. Djamil Padang pada tahun 2011-2012. Metode: Merupakan penelitian deskriptif. Data diperoleh dari riwayat kesehatan pasien yang didiagnosa glaukoma selama 2011-2012, termasuk jenis kelamin dan jenis glaukoma. Hasil: Jumlah pasien sebesar 203 orang dengan perbandingan laki-laki dan perempuan sebesar $54,86 \%: 45,14 \%$. Glaukoma primer sudut terbuka merupakan jenis glaukoma terbanyak $(50,25 \%)$, diikuti oleh glaukoma sekunder $(19,70 \%)$, glaukoma primer sudut penutupan $(11,50 \%)$, glaukoma juvenile $(10,84 \%)$, glaukoma kongenital $(4,4 \%)$, dan normotension glaukoma. Inflamasi adalah penyebab paling umum glaukoma sekunder (30\%). Glaukoma sering ditemukan pada kelompok usia di atas 40 tahun. Pengobatan untuk glaukoma primer sudut terbuka adalah medikamentosa $(63,72 \%)$ dan trabekulektomi $(36,28 \%)$. Terapi yang paling sering dilakukan pada glaukoma primer sudut tertutup adalah trabekulektomi (54,16\%). Kesimpulan: Glaukoma lebih banyak ditemukan pada laki-laki dan lebih sering ditemukan pada usia lebih dari 40 tahun. Glaukoma primer sudut terbuka adalah glaukoma yang paling sering ditemui dan inflamasi adalah penyebab paling umum glaukoma sekunder di RSUP DR. M. Djamil Padang. Pengobatan yang paling sering dilakukan pada glaukoma primer sudut terbuka adalah medikamentosa dan glaukoma primer sudut tertutup adalah trabekulektomi.

Kata kunci: Glaukoma, Glaukoma Primer Sudut Terbuka, Trabekulektomi

\begin{abstract}
Glaucoma refers to group of disease that have in common characteristic optic neuropathy with associated visual function loss. Objective: To describe distribution of glaucoma cases at Dr. M.Djamil Hospital Padang from 20112012. Method: Descriptive study. We obtained the data from medical record of patients whose diagnosed glaucoma during 2011-2012, includes gender and type of glaucoma Results: Total patients were 203. Male and female ratio was 54,86\%:45,14\%. Primary open angle glaucoma was the common form of glaucoma (50,25\%), followed by secondary glaucoma (19,70\%), Primary Angle Closure Glaucoma (PACG) (11,50\%), Juvenile Glaucoma (10,84\%), Congenital Glaucoma (4,4\%), and normotension glaucoma. Inflammation was the most common cause of secondary glaucoma (30\%). The disease was found to be more common in age group above 40 years. Treatment for POAG was medicamentosa $(63,72 \%$ and trabeculectomy $(36,28 \%)$. The most common treatment for PACG was trabeculectomy (54,16\%).Conclusion: The most common of glaucoma patient were male and more frequently found in over 40 years. $P O A G$ was the predominant form of glaucoma and inflammation was the most common cause of secondary glaucoma in M.Djamil Hospital Padang. The most common treatment for POAG was medicamentosa and PACG was trabeculectomy
\end{abstract}

Keywords: Glaucoma, POAG, Trabeculectomy

Affiliasi penulis : bagian ilmu kesehatan mata FK. Unand Korespondensi : Andrini Ariesti andriniariesti@yahoo.co.id Telp: [Company Phone]

\section{PENDAHULUAN}

Glaukoma adalah kelompok penyakit dengan karakteristik neuropati optik yang berhubungan dengan kehilangan fungsi penglihatan. Peningkatan tekanan intra okuler (TIO) merupakan faktor risiko utama dari penyakit ini. ${ }^{1,2}$

Klasifikasi glaukoma dibuat berdasarkan kelainan dasar yang mengakibatkan peningkatan tekanan intra okuler. Istilah primer dan sekunder sangat membantu dalam menentukan definisi glaukoma. Glaukoma primer tidak berkaitan dengan 
penyakit okuler atau sistemik yang mengakibatkan peningkatan resisitensi terhadap akuos outflow. Glaukoma primer biasanya mengenai kedua mata. Glaukoma sekunder berhubungan dengan penyakit atau sistemik yang berperan dalam penurunan akuos outflow. Penyakit yang menyebabkan glaukoma sekunder sering asimetris atau unilateral. Glaukoma diklasifikasikan menjadi glaukoma sudut terbuka, glaukoma sudut tertutup dan glaukoma developmental. ${ }^{1,2,3}$

Glaukoma merupakan penyebab utama kebutaan irreversible di dunia. Glaukoma menimpa hampir 67 juta penduduk di dunia dimana 10\% (6,6 juta) diantaranya mengalami kebutaan. ${ }^{4,5}$ Efek sosial dan ekonomi dari glaukoma sangat besar diantaranya kesulitan untuk melamar pekerjaan, aktivitas seharihari, isolasi sosial dan depresi. ${ }^{6}$ Prevalensi glaukoma bervariasi pada masing-masing populasi. Di Eropa dan Amerika Utara Primary Open Angle Glaucoma (POAG) merupakan tipe glaukoma yang dominan. Prevalensi POAG di Amerika Serikat diperkirakan 2,22 juta penduduk $(1,86 \%){ }^{7}$ Hampir setengah dari seluruh populasi penderita glaukoma berada di Asia. Proporsi terbesar penderita di Asia (25\%) mengalami kebutaan bilateral yang disebabkan Primary Closed Angle Glaucoma (PACG) dan 10\% disebabkan POAG. Prevalensi glaukoma di Tanzania dan Afrika Selatan dilaporkan 5\%. Tipe glaukoma yang dominan adalah POAG. ${ }^{8,9}$

\section{TUJUAN PENELITIAN}

Tujuan dari penelitian ini adalah:

1. Untuk mengetahui pola glaukoma di RS M Djamil Padang

2. Untuk mengetahui faktor penyebab glaukoma sekunder

3. Untuk mengetahui penatalaksanaan glaukoma di RS M Djamil Padang

\section{METODE DAN BAHAN PENELITIAN}

Metode yang digunakan dalam penelitian in adalah retrospektif deskriptif. Data diambil dari rekam medis dengan diagnosis glaukoma dan dikelompokan menurut umur, jenis kelamin, tipe glaukoma, dan penatalaksanaan glaukoma.

\section{HASIL PENELITIAN}

Selama periode 2011-Desember 2012 terdapat 203 pasien dengan diagnosis glaukoma di bagian mata RS Dr M Djamil Padang.

Tabel 1. Distribusi Pasien Glaukoma Menurut Jenis Kelamin

\begin{tabular}{l|l|l}
\hline Jenis Kelamin & Jumlah & Persentase (\%) \\
\hline Laki-laki & 110 & 54,19 \\
Perempuan & 93 & 45,81 \\
\hline Total & 203 & 100 \\
\hline
\end{tabular}

Angka kejadian glaukoma lebih besar pada laki-laki (\%) dibanding perempuan (\%)

Tabel 2. Distribusi Pasien Glaukoma Berdasarkan Tipe Glaukoma

\begin{tabular}{l|l|l}
\hline Tipe Glaukoma & Jumlah & $(\%)$ \\
\hline POAG & 102 & 50,25 \\
PACG & 24 & 11,82 \\
Normotension Glaucoma & 6 & 2,9 \\
Glaukoma Juvenil & 22 & 10,84 \\
Glaukoma Kongenital & 9 & 4,4 \\
Glaukoma Sekunder & 40 & 19,70 \\
\hline Total & 203 & 100 \\
\hline Dari 203 kasus glaukoma, tipe glaukoma terbanyak \\
yang ditemukan adalah POAG (50,25\%).
\end{tabular}

Tabel 3. Distribusi POAG Menurut Jenis Kelamin

\begin{tabular}{l|l|l}
\hline Jenis kelamin & Jumlah & $(\%)$ \\
\hline Laki-laki & 59 & 57,84 \\
Perempuan & 43 & 42,16 \\
& & \\
\hline Total & 102 & 100 \\
\hline Angka kejadian PAG lebih besar pada laki-laki
\end{tabular}

$(57,86 \%)$ dibanding perempuan

Tabel 4. Distribusi POAG Menurut Umu

\begin{tabular}{l|l|l}
\hline Umur (tahun) & Jumlah & Persentase (\%) \\
\hline $40-49$ & & \\
$50-59$ & 11 & 10,78 \\
$60-69$ & 23 & 22,55 \\
$\geq 70$ & 38 & 37,25 \\
\hline Total & 30 & 29,41 \\
\hline
\end{tabular}

Frekuensi POAG terbanyak ditemukan pada dekade umur 60-69 tahun $(37,25 \%)$

Tabel 5. Distribusi PACG Menurut Jenis Kelamin

\begin{tabular}{l|l|l}
\hline Jenis kelamin & Jumlah & Persentase \\
\hline $\begin{array}{l}\text { Laki-laki } \\
\text { Perempuan }\end{array}$ & 9 & 62,5 \\
& 97,5 \\
\hline Total & 24 & 100 \\
\hline $\begin{array}{l}\text { PACG ditemukan sebanyak 24 kasus (11,82\%) dan } \\
\text { lebih banyak ditemukan pada laki-laki (62,5\%) } \\
\text { dibanding perempuan (37,5\%). }\end{array}$
\end{tabular}

Tabel 6. Distribusi PACG Menurut Umur

\begin{tabular}{l|l|l}
\hline Umur & Jumlah & Persentase \\
\hline $40-49$ & 3 & 12,5 \\
$50-59$ & 11 & 45,83 \\
$60-69$ & 3 & 12,50 \\
$\geq 70$ & 7 & 29,16 \\
\hline Total & 24 & 100 \\
\hline
\end{tabular}


PACG paling sering terjadi pada dekade umur $50-59$ tahun $(45,83 \%)$.

\section{Tabel 7.Distribusi Glaukoma Sekunder Berdasarkan Penyebab}

\begin{tabular}{l|l|l}
\hline Faktor Penyebab & Jumlah & Persentase \\
& & \\
\hline Trauma & 8 & 20 \\
Inflamasi & 12 & 30 \\
Neovaskular & 3 & 7,5 \\
Pseudoexfoliasi & 6 & 15 \\
Lens Induced & 11 & 27,5 \\
& & \\
\hline Total & 40 & 100 \\
\hline Kasus glaukoma
\end{tabular}

Kasus glaukoma sekunder berjumlah 40 (\%). Penyebab terbanyak adalah inflamasi dengan jumlah 12 kasus (30\%)

Tabel 8. Penatalaksanaan Primary Open Angle Glaucoma (POAG)

\begin{tabular}{|c|c|c|}
\hline Penatalaksanaan & Jumlah & $\%$ \\
\hline Medikamentosa & 65 & 63,72 \\
\hline Trabekulektomi & 37 & 36,28 \\
\hline Total & 102 & 100 \\
\hline Penatalaksanaan & \multicolumn{2}{|c|}{$\begin{array}{l}\text { terbanyak } \\
(63,72 \%) \text { dan } \begin{array}{l}\text { POAG } \\
\text { trabekulektom }\end{array}\end{array}$} \\
\hline
\end{tabular}

Tabel 9. Penatalaksanaan Primary Angle Closure Glaucoma (PACG)

\begin{tabular}{l|l|l}
\hline Penatalaksanaan & Jumlah & $\%$ \\
\hline Trabekulektomi & 13 & 54,16 \\
Iridektomi & 3 & 12,50 \\
Menolak ditindak & 8 & 33,34 \\
& & \\
\hline Total & 24 & 100 \\
\hline $\begin{array}{l}\text { Penatalaksanaan PACG terbanyak adalah } \\
\text { trabekulektomi (54,16\%) }\end{array}$
\end{tabular}

\section{DISKUSI}

Selama periode januari 2011 - Desember 2012 didapatkan sebanyak 203 pasien dengan diagnosis glaukoma di bagian mata RS M Djamil Padang.

Diagnosis glaukoma ditegakkan dengan memperhatikan adanya glaukomatous optik disk, defek lapangan pandang yang spesifik untuk glaukoma, pemeriksaan gonioskopi, dan tonometri applanasi.

Dari data yang didapatkan tipe glaukoma yang terbanyak adalah POAG (50,25\%). POAG mewakili masalah kesehatan masyarakat secara signifikan. Perkiraan prevalensi POAG di United States pada individu dengan usia di atas 40 tahun adalah $1,86 \%$ berdasarkan meta analisis studi berbasis populasi. POAG merupakan penyebab utama kebutaan di United States dan frekuensi terbanyak penyebab kebutaan irreversible pada kulit hitam. ${ }^{7} \mathrm{Di}$ India, prevalensi POAG meningkat sesuai dengan bertambahnya usia pada semua studi. Aravind Comprehensive Eye Study mendapatkan prevalensi glaukoma adalah 2,6\% dan POAG $1,7 \% .^{5}$ Penelitian Rahman dkk di Bangladesh mendapatkan prevalensi glaukoma adalah 3,1\% dengan $75 \%$ diantaranya adalah POAG. ${ }^{10}$ Tajimi Study di Jepang mendapatkan angka yang lebih tinggi lagi, yaitu 3,9\%, 0,6\%, 0,5\%, dan $5 \%$ berturut-turut untuk POAG, PACG, glaukoma sekunder, dan semua tipe glaukoma pada populasi di atas 40 tahun. ${ }^{11,12}$ Rotchford dkk di Afrika Selatan (Temba Glaucoma Study) mendapatkan prevalensi semua glaukoma 5,3\%, POAG (2,9\%), dan glaukoma sekunder $(2,0 \%){ }^{13}$ The World Health Organization (WHO) melakukan analisis untuk memperkirakan prevalensi, insiden, dan tingkat keparahan berbagai tipe glaukoma berbasis worldwide. Berdasarkan data yang dikumpulkan pada akhir tahun 1980an sampai awal 1990an, WHO memperkirakan populasi global yang mempunyai TIO tinggi $(>21 \mathrm{mmHg}$ ) adalah 104,5 juta, dan insiden POAG diperkirakan diperkirakan 2,4 juta penduduk per tahun. ${ }^{8}$

Dari perspektif kesehatan masyarakat, lebih dari $90 \%$ penderita glaukoma tidak mengetahui memiliki riwayat glaukoma, hal ini menunjukkan banyak kasus yang tidak terdiagnosis. Lebih dari $97 \%$ POAG tidak terdiagnosis, dibandingkan dengan kasus PACG dan glaukoma sekunder yang hanya $75 \%$ tidak terdiagnosis. Perbedaan ini diperkirakan karena PACG lebih simptomatis dibandingkan POAG. POAG merupakan penyakit kronis, slowly progressive, dan tidak nyeri. Hal ini membuat penyakit ini kurang disadari oleh si penderita sendiri, sampai terjadi kondisi yang lanjut. ${ }^{14}$

Pada penelitian ini prevalensi glaukoma terbanyak didapatkan pada umur di atas 40 tahun. Banyak penelitian population based yang mendapatkan adanya peningkatan prevalensi POAG dengan bertambahnya usia. Pada Baltimore Eye Survey, prevalensi glaukoma pada kulit putih 3,5 kali lipat pada individu umur 70an dibanding umur 40an. ${ }^{1}$ Singapore Malay Eye Study juga menemukan bahwa prevalensi glaukoma meningkat dengan bertambahnya usia pada penduduk Malaysia. ${ }^{14}$ Pada Rotterdam Study menunjukkan prevalensi POAG sebesar 0,8\% dan Barbados Eye Study menunjukkan prevalensi POAG sebesar $7 \%$ pada individu dengan usia lebih dari 40 tahun. $^{15}$

Pada glaukoma sudut tertutup, dengan meningkatnya usia akan menyebabkan penurunan kedalaman dan volume kamera okuli anterior. Perubahan ini menjadi predisposisi terjadinya blok pupil. Prevalensi blok pupil yang menginduksi terjadinya glaukoma sudut tertutup akan meningkat dengan bertambahnya usia. Glaukoma sudut tertutup akut sering terjadi pada usia 55-65 tahun. ${ }^{1}$

Pada penelitian ini juga didapatkan penderita glaukoma terbanyak adalah laki-laki (51,19\%). Pada Framingham dan Barbados eye studies, laki-laki memiliki rasio lebih besar menderita POAG. 
Sedangkan The Sweden, St Lucia dan Blue Mountains studies melaporkan penderita perempuan lebih banyak. Berdasarkan hasil yang bervariasi ini, jenis kelamin tidak dianggap sebagai faktor risiko POAG. ${ }^{1}$

Pada penelitian ini, PACG ditemukan sebanyak 24 kasus $(11,82 \%)$ dan paling sering ditemukan pada laki-laki (57,84\%) dibanding perempuan $(42,15 \%)$. Frekuensi terbanyak ditemukan pada dekade umur 50-59 tahun (37,25\%). Glaukoma sudut tertutup akut dilaporkan lebih sering terjadi pada wanita dibanding pria. Pada beberapa survey populasi menunjukkan bahwa wanita memiliki peningkatan risiko terjadinya glaukoma sudut tertutup. Studi pada mata yang normal menunjukkan wanita memiliki kamera okuli anterior yang lebih dangkal dibanding pria. ${ }^{1,2}$

Glaukoma sekunder ditemukan $19,70 \%$ dari seluruh penderita glaukoma, 20\% diantaranya disebabkan oleh trauma, 30\% disebabkan inflamasi, $27,5 \%$ disebabkan oleh lensa (lens induced glaucoma), $7,5 \%$ disebabkan oleh neovaskularisasi dan $15 \%$ ditemukan glaukoma pseudoeksfoliasi. Temba Glaucoma Study mendapatkan prevalensi glaukoma sekunder $2,0 \%$ dengan $45 \%$ diantaranya adalah glaukoma eksfoliasi dan $20 \%$ karena trauma (angle recess). ${ }^{13}$ Sedangkan Tajimi Study di Jepang mendapatkan $0,3 \%$ untuk prevalensi glaukoma sekunder, dengan $66,6 \%$ adalah uveitic glaucoma, kemudian $16,6 \%$ masing-masingnya glaukoma sekunder karena trauma dan neovaskuler. ${ }^{12}$

Penatalaksanaan POAG adalah medikamentosa. Tindakan operatif dilakukan jika terdapat indikasi. Pada penelitian ini penatalaksanaan POAG yang terbanyak adalah medikamentosa $(63,72 \%)$ dan trabekulektomi (36,28\%). Penatalaksanaan PACG terbanyak adalah trabekulektomi $(54,16 \%)$ dan terdapat 8 orang pasien yang menolak untuk dilakukan tindakan operatif.

\section{KESIMPULAN}

1. Pada periode Januari 2011-Desember 2012 didapatkan penderita glaukoma sebanyak 203 pasien.

2. POAG merupakan tipe glaukoma terbanyak

3. Inflamasi merupakan penyebab terbanyak glaukoma sekunder

4. Pada penelitian ini penatalaksanaan POAG yang terbanyak adalah medikamentosa dan trabekulektomi

5. Penatalaksanaan PACG terbanyak adalah trabekulektomi

\section{SARAN}

Perlunya dilakukan screening oleh tenaga kesehatan mengingat masih banyak penderita yang masih tidak terdeteksi dan tidak terdiagnosis glaukoma pada tingkat daerah.

\section{DAFTAR PUSTAKA}

1. Skuta GL, Cantor BL. Introduction to Glaucoma: Terminology, Epidemiology and Heredity. In: Glaucoma. American Academy
Ophthalmology. Section 10. San Fransisco, 2011.p.7-16

2. Becker- Shaeffer's.Glaucoma in The World In: Diagnosis and Therapy of the Glaucoma 8 th edition. Ed. Stamper RL, Lieberman MF, Drake MV, Mosby St. Louis, Philadelphia.2009.p.1-6

3. Foster et al. The Definition and Classification of Glaucoma in Prevalence Surveys. British Journal of Ophthalmology.2002. 86:238-242.

4. Sharaawy TM et al. Glaucoma in The World. In: Glaucoma Medical Diagnosis \& Therapy. Elsevier-Saunder. Philadephia. 2009.p.3-37

5. Krishnadash R, Puthuran GV. Prevalence of Glaucoma in India and The World. Tamil Nadu Journal of Ophthalmology. Vol.47, Issue.4. December 2009.p.13-16

6. Freeman $\mathrm{E}$ et al. Glaucoma and Mobility Performance. Ophthalmology.2007.115: 233238

7. Friedman et al. Prevalence of Open Angle Glaucoma among Adults in the United States. Archive of Ophthalmology. 2004.122:532-538

8. Quigley HA, Broman T. Number of People With Glaucoma Worldwide in 2010 and 2020. British Journal of Ophthalmology. 2006. 90; 262-267

9. Coleman Al. Epidemiology of Glaucoma. In: Glaucoma Science and Practice. Thieme Medical Publisher. 2003.p. 2-11.

10. Rahman MM et al. The Prevalence of Glaucoma in Bangladesh: a Population Based Survey in Dhaka Vision. British Journal of Ophthalmology. 2004. 88; 14931497

11. Iwase A, Suzuki y, Araie M, Yanamoto T, Abe $\mathrm{H}$. The Prevalence of Primary Open Angle Glaucoma in Japanese. The Tajimi Study. Ophthalmology. 2004. 111: 1641-1648.

12. Iwase A, Suzuki y, Araie M, Yanamoto T, Abe H. The Tajimi Study Report 2. Ophthalmology The Prevalence of Primary Angle Closure Glaucoma and Secondary Glaucoma in Japanese Population.2005. 112: 1661-1669

13. Rotchford AP, Kirwan JF, Muller MA, Johnson GJ, Roux P. Temba Glaucoma Study: A Population Based-Cross Sectional Survey in Urban South Africa. Ophthalmology. 2003. 110: 376-382

14. Shen SY et al. Prevalence and Types of Glaucoma in Malay People: The Singapore Malay Eye Study. Invest. Ophthalmol. Vis. Sci. September 2008 vol. 49 no. 9 3846-3851

15. Hyman L, Wu S, Connel AM, Schachat A. Prevalence and Causes of Visual Impairment in the Barbados Study. Ophthalmology. 2001.108;1751-1756 